\title{
Underwriting Systematic Risk and Profit Margin in Fuzzy CAPM and ICAPM Models: The Case of Aviation Coverage
}

\author{
Li-Hua Lai \\ National Kaohsiung First University of Science and Technology Kaohsiung \\ E-Mail: lihua@ccms.nkfust.edu.tw
}

\begin{abstract}
Airlines are the business of transporting passengers in which the safety and risk have always been important. We use the fuzzy CAPM and fuzzy ICAPM models to investigate the underwriting systematic risk and profit margin of aviation transportation, in which the parameters of membership function are the asymmetric triangular fuzzy number. We calculate the underwriting systematic risk and profit margin of aviation and show that the value of underwriting systematic risk in both of CAPM and in ICAPM are positive and, while the underwriting profit margin of aviation is positive in CAPM it is negative in ICAPM. The results mean that there is a positive relationship between the return rate of underwriting and rate of market, and the return of $\mathrm{P} / \mathrm{L}$ insurer is made on investments, not on the underwriting in the aviation insurance, which could be used to perform the forecasting of the underwriting profit margin and underwriting systematic risk. Our results show that the prediction model of underwriting risk and insurance price in the fuzzy environment with skew factor becomes more rational and elastic than that in the crisp environment.
\end{abstract}

Keywords: CAPM, ICAPM, Underwriting Systematic Risk, Underwriting Profit Margin

\section{INTRODUCTION}

Airlines are the business of transporting passengers in which the safety and risk have always been important. The contingency event will unavoidably happen in aviation transportation. The accident rate for airline travel is lower than for any other modes of transportation, nevertheless, when accidents do happen they can cause considerable financial (Brooker, 2004) as well as emotional distress. Airlines choose to avoid the financial distress by purchasing insurance against loss-through-accident 
and will seek to provide safeguard in insurance (Margo, 1996; Wells and Chadbourne, 2000). The traditional methods of ratemaking, which depend on rule of subjective experience, are not taken underwriting profit and investment income of an insurance company into considerations. It ignores the importance of investment income of overall profits. These profit benefits should be feed-backed to shareholders and holder of policy in the market. In this paper we will use the CAPM and ICAPM models to investigate the fuzzy underwriting profit margin and underwriting systematic risk of aviation.

The financial pricing model has replaced traditional assessment techniques for underwriting profit margin and underwriting systematic risk in property-liability (P/L) insurers. The Capital Asset Pricing Model (CAPM) developed in the mid-1960s by Sharpe (1964). Lintner(1965), and Mossin (1966) has typically been used to select the Target Total Rate of Return (TRR). The first model of this type was developed by Ferrari (1968), which presents the basic algebraic model of the insurer but does not link the concept of market equilibrium. In addition, the company in aviation industry also quite cares about their systematic risk values are calculated and compared (Turner and Morrell, 2003). An important advance in insurance financial pricing was the linkage of algebraic model of insurance firm with the capital asset pricing model. The model has been applied to insurance by Cooper (1974). Hill and Modigliani (1987) had extended CAPM to P/L insurance which is named as insurance CAPM (ICAPM) (Urrutia, 1986).

In this paper we will investigate the CAPM and ICAPM models under the fuzzy environment and, furthermore, the parameters of membership function therein may be the asymmetric triangular fuzzy numbers. Note that the fuzzy set theory (FST) was introduced by Zadeh (1965). FST has been used in insurance price problems that require much actuarial subjective judgment. It has been over 20 years since the first article on fuzzy logic has been applied to insurance by DeWit (1982). The article sought to quantify the fuzziness in underwriting. Since then, the universe of discourse has expanded considerably and now includes fuzzy logic applications in non-life insurance involving classification, projected liabilities, underwriting, investments and pricing. Therein, Lemaire (1990) applied fuzzy logic to underwriting and reinsurance decisions. Derrig and Ostazewski $(1994,1995)$ showed that fuzzy clustering methods are suitable for risk classification. Young (1996) applied fuzzy reasoning to insurance rate decisions. Cummins and Derrig (1997) had used fuzzy decision to evaluate several econometric methods of claim cost forecasting and address the financial pricing of property-liability insurance contracts. Lai (2006) showed that the 
best-fitting parameters of the model from underwriting profit margin of P/L insurance are asymmetric triangular fuzzy numbers. Lai (2007) documented the skew factors and ranking with risk attitudes of the evaluator to the underwriting risk in each line are determined, which could be used to perform the forecasting of the underwriting systematic risk. Lai (2008) suggest that the lower and upper limits of the fuzzy transportation underwriting systematic risk associated to these fuzzy numbers and show the underwriting of most lines are below normal market risk in Taiwan, except that of the compulsory automobile liability. Thus, this paper also estimate the underwriting beta value for the transportation various lines and show that they may be positive or negative. This paper is the first of its kind and as a result, it contributes to understanding of the different effect may be calculated the underwriting systematic risk and profit margin of the aviation and show that the value of underwriting systematic risk in both of CAPM and in ICAPM as well as fills the existing gap between theoretical and empirical evidence.

In section II, after describing the Fuzzy CAPM and Fuzzy ICAPM models, we apply the fuzzy set theory to the CAPM and ICAPM models and present the formula to calculate the underwriting systematic risk and profit margin of aviation transportation under the fuzzy environment, in which the parameters of membership function may be the asymmetric triangular fuzzy number. In section III we first use the ten-year data of insurance company to calculate the lower and upper limits of underwriting profit margin, and then use the Centroid method of defuzzification (Roubens and Vincke, 1988; Yager,1994) to convert them into the crisp values. After comparing to the underwriting profit margins in the crisp environment we determine the best-fitting parameters of skew factors in asymmetric triangular fuzzy number. Using the found skew factors we present in section IV the calculated underwriting systematic risk and profit margin of aviation of the fuzzy CAPM and fuzzy ICAPM models. The results show that the value of underwriting systematic risk in CAPM is larger than that in ICAPM, which mean that there is a positive relationship between the return rate of underwriting rate and market rate in aviation insurance. We also find that the underwriting profit margin of aviation is positive in CAPM and is negative in ICAPM. This means that the return of $P / L$ insurer is made on investments, not on underwriting in aviation insurance (Urrutia, 1986). 


\section{CAMP and ICAPM MODELS IN FUZZY ENVIRONMENT}

The ICAPM of Hill and Modigliani (Hill and Modigliani, 1987) is given economic content by assuming that the equilibrium expected return on the $\mathrm{P} / \mathrm{L}$ insurer's underwriting is determined. We will consider the CAPM and ICAPM under fuzzy environment, in which the parameters $r_{f}, r_{u}, r_{m}, f_{u}$ and $f_{f}$ are assumed to be the asymmetric triangular fuzzy numbers (TFN) in general. Under the asymmetric fuzzy environment the fuzzy parameters become

$W_{i}=\left[\mathrm{W}_{i}^{L}, \mathrm{~W}_{i}^{C}, \mathrm{~W}_{i}^{U}\right]$

such that

$W_{\alpha, i}=\left[\mathrm{W}_{\alpha, i}^{L}, \mathrm{~W}_{\alpha, i}^{U}\right]=\left[\mathrm{W}_{i}^{L}+\alpha\left(\mathrm{W}_{i}^{C}-\mathrm{W}_{i}^{L}\right), \mathrm{W}_{i}^{U}-\alpha\left(\mathrm{W}_{i}^{U}-\mathrm{W}_{i}^{C}\right)\right]$

in which $w_{\alpha, i}$ are them fuzzy parameters $\left(r_{f}\right)_{\alpha, i},\left(r_{m}\right)_{\alpha, i},\left(f_{u}\right)_{\alpha, i},\left(f_{f}\right)_{\alpha, i}$. The value of $\left(\mathrm{W}_{i}^{U}-\mathrm{W}_{i}^{C}\right) /\left(\mathrm{W}_{i}^{C}-\mathrm{W}_{i}^{L}\right)$ in $(2.2)$ is defined to be the skew factor $\mathrm{k}$.

The underwriting profit margin (UPM) in the fuzzy environment can now be expressed as:

$(\mathrm{UPM})_{\alpha, i}=\left(1-\mathrm{t}_{U}\right)^{-1}\left(f_{u}\right)_{\alpha, i}\left(1+\left(f_{f}\right)_{\alpha, i} \mathrm{t} a-\left(f_{f}\right)_{\alpha, i}\right)\left(r_{f}\right)_{\alpha, i}+\beta_{u}\left(\mathrm{E}\left(r_{m}\right)-\left(r_{f}\right)_{\alpha, i}\right)$

By general results on empirical processes, the fuzzy ICAPM and fuzzy CAPM can be estimated by

$$
\begin{aligned}
& (\mathrm{UPM})_{\alpha, i}^{I C A P M}=(\mathrm{UPM})_{\alpha, i} \quad \text { if } \mathrm{t}_{U}, \mathrm{t} a, f_{f}, f_{u}>0 \\
& (\mathrm{UPM})_{\alpha, i}^{C A P M}=(\mathrm{UPM})_{\alpha, i} \text { if } \mathrm{t}_{U}, \mathrm{t} a, f_{f}, f_{u}=0
\end{aligned}
$$

where $(\mathrm{UPM})_{i}$ is the sample ${ }^{i}$ of underwriting profit margin with different tax rates for underwriting and investment. The variables used in the above formulas include:

$$
\begin{array}{ll}
\beta_{u} & : \text { underwriting systematic risk } \\
r_{u} & : \text { underwriting rate of return } \\
r_{m} & : \text { market rate of return }
\end{array}
$$


$r_{f} \quad$ : risk-free rate of return

$\mathrm{E}\left(r_{m}\right)$ :expected return on the market portfolio

$f_{u} \quad$ : insurance underwriting leverage factor

$f_{f} \quad$ : insurance financial leverage factor

$\mathrm{t}_{U} \quad$ : tax rate on underwriting income

$\mathrm{t} a \quad$ : tax rate on investment income

In the next section we will apply the above formula to investigate the insurances of aviation from the fuzzy CAPM and fuzzy ICAPM models by using the ten-year data in Taiwan. We first calculate the lower and upper limits of the underwriting profit margins, i.e. (UPM) $)_{\alpha, i}^{L}$ and (UPM) $)_{\alpha, i}^{U}$, associated to the various values of skew factor k. After comparing them with the underwriting profit margins in the crisp environment (see the eq. (3.1)) we determine the best-fitting parameters of skew factors in asymmetric triangular fuzzy number.

\section{SKEW FACTORS}

After substituting the ten-year data of the aviation insurance from a $\mathrm{P} / \mathrm{L}$ insurance company in Taiwan into equation (2.3) we can obtain the values of $(\mathrm{UPM})_{\alpha, i}^{L}$ and $(\mathrm{UPM})_{\alpha, i}^{U}$, for various skew factor k. To find the best-fitting skew factor we first denote the function $(\triangle \mathrm{UPM}(\mathrm{k}))$ as the ten-year average of the standard deviation of UPM [Lai, 2006].

In figure 1 we plot the k-dependence of $(\triangle U P M M(k))$ in the aviation's underwriting systematic risk and profit margin in fuzzy CAPM and fuzzy ICAPM Models. It then sees that the best-fitting parameters of the fuzzy CAPM is $k=0.89$ and that of fuzzy ICAPM is $\mathrm{k}=0.91$. 


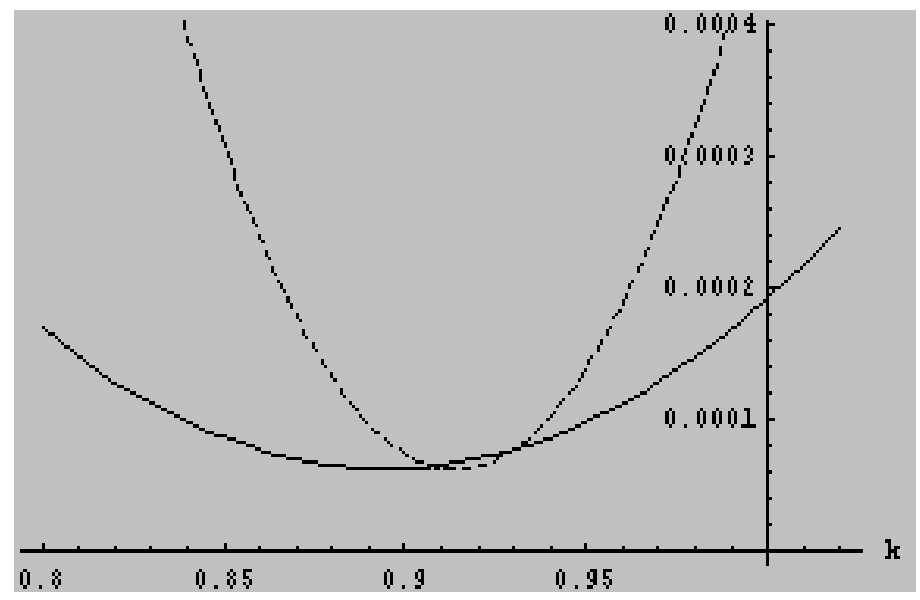

Figure 1 k-dependence of $(\triangle \mathrm{UPM}(\mathrm{k}))$. Solid line represents that of CAPM and dashing line represents that of ICAPM

\section{UNDERWRITING SYSTEMATIC RISK AND PROFIT MARGIN IN FUZZY CAPM AND FUZZY ICAPM MODELS}

Now we will use the found skew factors to calculate the underwriting systematic risk and profit margin of aviation in fuzzy CAPM and fuzzy ICAPM respectively. After using the Centroid method of defuzzification we can from the calculated values of the lower and upper limits of the underwriting systematic risk in CAPM and ICAPM models to find the corresponding crisp values of fuzzy environment. In table 1 , we present these values of $\beta_{u}$.

Table 1 Values of $\beta_{u}$ in aviation
\begin{tabular}{|c|c|}
\hline model & $\beta_{u}$ \\
\hline CAPM & $0.17114 \%$ \\
\hline ICAPM & $0.17108 \%$ \\
\hline
\end{tabular}

Above results show that the value of underwriting systematic risk in both of CAPM and in ICAPM are positive. This means that there is a positive relationship between the return rate of underwriting rate and market rate in aviation insurance.

In the same way, after using the Centroid method of defuzzification we can from the calculated values of the lower and upper limits of the underwriting profit margins to find the corresponding crisp values of fuzzy environment. In table 2, we present these values in the case of best-fitting value of skew factor. 
Table 2 Crisp values of UPM in fuzzy CAPM and ICAPM models

\begin{tabular}{|l|c|c|c|c|c|c|c|c|c|c|}
\hline year & 1 & 2 & 3 & 4 & 5 & 6 & 7 & 8 & 9 & 10 \\
\hline UPM $_{\text {CAPM }}$ & 0.98 & 0.95 & 0.87 & 0.81 & 0.85 & 0.68 & 0.67 & 0.52 & 0.31 & 0.21 \\
\hline UPM $_{\text {ICAPM }}$ & -0.47 & -0.58 & -0.43 & -0.48 & -0.63 & -0.68 & -0.74 & -0.28 & -0.52 & -0.13 \\
\hline
\end{tabular}

From the table 2 we have seen that while the underwriting profit margin of aviation is positive in CAPM it is negative in ICAPM. The results mean that the return of $\mathrm{P} / \mathrm{L}$ insurer is made on investments, not on underwriting in aviation insurance (Fairley, 1979; Urrutia, 1986). It is interesting to see that the insurance price $\mathrm{R}$ may be expressed as (McClenahan, 1996)

$R=\left(R_{L}+R_{F}\right)\left(1-\left(R_{V}-R_{P}-U P M\right)\right)^{-1}$

in which $\mathrm{RL}$ is the loss ratio, $\mathrm{RF}$ the fixed expense ratio, $\mathrm{RV}$ the variable expense ratio, and RP is the profit ratio. Therefore in the fuzzy CAPM, as UPM is positive it will decrease the insurance price, on the other hand, in the fuzzy ICAPM, as UPM is negative, it will increase the insurance price. This property may be the special property of the input data from the insurance company in Taiwan.

\section{CONCLUSION}

In this paper we have used the CAPM and ICAPM models to investigate the fuzzy underwriting profit margin and underwriting systematic risk of aviation transportation, in which the parameters of membership function may be the asymmetric triangular fuzzy number. We first adopt the ten-year data of insurance company to calculate the lower and upper limits of underwriting profit margin and then and use the Centroid method of defuzzification to convert them into the crisp values through. We compare them with the underwriting profit margins in the crisp environment and determine the best-fitting parameters of skew factors in asymmetric triangular fuzzy number. Using the found skew factors we therefore present the calculated underwriting systematic risk and profit margin of aviation. The results show that the value of underwriting systematic risk in both of CAPM and in ICAPM are positive, which means that there is a positive relationship between the return rate of underwriting rate and market rate in aviation insurance. As the calculated underwriting profit margin of aviation is positive in CAPM and is negative in ICAPM we conclude that the return of $\mathrm{P} / \mathrm{L}$ insurer is made on investments, not on underwriting in aviation insurance. Finally, as UPM is positive in the fuzzy CAPM it will decrease the insurance price. On the other hand, as UPM is negative in the fuzzy ICAPM it will increase the insurance price. 


\section{ACKNOWLEDGMENTS}

The author is grateful to the two anonymous reviewers for Contemporary Management Research for their comments on an earlier version of this paper.

\section{REFERENCES}

Brooker, P. (2004). Future Air Traffic Management Systems and Financial Decision-making Constraints. Transportation, 31,1-20.

Cooper, R.W. (1974). Investment Return and Property-Liability Insurance Rate Making Homewood. Illinois: Richard D Irwin.

Cummins, J.D. and Derrig, R.A. (1997). Fuzzy Financial Pricing of Property-Liability Insurance. North American Actuarial Journal, 1(4), 21-40.

Derrig, R.A. and Ostazewski, K.M. (1994). Fuzzy Techniques of Pattern Recognition in Risk and Claim Classification. in: Proceedings of the 4th AFIR International Colloquium, 1, 141-171.

Derrig, R.A. and Ostazewski, K.M. (1995). Fuzzy Techniques of Pattern Recognition in Risk and Claim Classification. Journal of Risk and Insurance, 62, 447-482.

DeWit, G.W. (1982). Underwriting and Uncertainty. Insurance: Mathematics and Economics, 1, 277-285.

Fairley, W. B. (1979). Investment Income and Profit Margin in Property Liability Insurance: Theory and Empirical Results. Bell Journal of Economics, 10, 192-210.

Ferrari, J.R. (1968). The Relationship of Underwriting, Investments, Leverage and Exposure to Total Return on Owners' Equity. PCAS, 55, 295-302.

Hill, R.D. and Modigliani, F. (1987). The Massachusetts Model of Profit Regulation in Non-life Insurance: An Appraisal and Extensions. In Cummins, J.D. and Harrington, S.A. (Eds), Fair Rate of Return in Property-Liability Insurance (pp. 27-54). Kluwer-Nijhoff Boston.

Lai, L.H. (2006). Underwriting Profit Margin of P/L Insurance in the Fuzzy-ICAPM. Geneva Risk and Insurance Review, 31(1), 23-34.

Lai, L.H. (2007). Fuzzy Underwriting Systematic Risk of Insurance: Some Evidence from Taiwan.Academy of Taiwan Business management Review, 3(2), 57-64.

Lai, L. H. (2008). An Evaluation of Fuzzy Transportation Underwriting Systematic Risk. Transportation Research Part A, 1231-1237.

Lemaire, J. (1990). Fuzzy Insurance.ASTIN Bulletin, 20, 33-55. 
Lintner, J. (1965). The Valuation of Risk Assets and Selection of Risky Investment in Stock Portfolios and Capital Budgets. Review of Economics and Statistics, 47, 13-37.

Margo, R. (1996). Aspects of Insurance in Aviation Finance. Journal of Air Law and Commerce, 62, 423-478.

McClenahan, C. L. (1996). Ratemaking Foundations of Casualty Actuarial Science, Casualty Actuarial Society, Arlington, VA.

Mossin, J. (1966). Equilibrium in a Capital Market. Econometric, 34, 768-783.

Roubens, M. and Vincke, P. (1988). Fuzzy Possibility Graphs and Their Application to Ranking Fuzzy Numbers. In Kacpizk, J. and Reukens, M. (Eds), Non-Conventional Preference Relations in Decision Making (pp. 119-128). New York, Springer-Verlag.

Sharpe, W.F. (1964). Capital Asset Prices: A Theory of Market Equilibrium under Conditions of Risk. Journal of Finance, 19, 425-442.

Turner, S. and Morrell, P. (2003). An Evaluation of Airline Beta Values and Their Application in Calculating the Cost. Journal of Air Transport Management, 9, 201-209.

Urrutia, J.L. (1986). The Capital Asset Pricing Model and the Determination of Fair Underwriting Returns for the Property-Liability Insurance. Geneva Papers on Risk and Insurance, 11, 44-60.

Wells, A. and Chadbourne, B. (2000). Introduction to Aviation Insurance and Risk Management. Florida: Krieger.

Yager, R.R. and Filev, D.P. (1994). Essentials of Fuzzy Modeling and Control. New York: John Wiley and Sons, Inc..

Young, V.R. (1996). Insurance Rate Changing: A Fuzzy Logic Approach. Journal of Risk and Insurance, 63, 461-483.

Zadeh, L.A. (1965). Fuzzy Sets.Information and Control, 8, 338-353. 
